\title{
Prácticas del control previo para evitar corrupciones
}

\section{Prior control practices to avoid corruption}

\author{
Gema Viviana Paula Alarcón. ${ }^{1}$ \& Doris Nataly Gallegos Santillán. ${ }^{2}$
}

\section{DOI: https://doi.org/10.33262/visionariodigital.v5i4.1896}

\begin{abstract}
In Ecuador in recent years, the commission of acts of corruption has been observed, especially in public contracting, which, for the most part, is subject to overpricing, which is why it is proposed as Objectives: Participate in special examinations of contracting of Certain work, through the Bidding process, having confirmed that there was a surcharge, a contract that was addressed from the authorities and members of the Contracting Committee, using out-of-time hours of attention to the public; and the second, by training small and medium-sized farmers, carried out through a public tender for lower-value offers, demonstrating compliance with the efficiency, effectiveness and economy policies established by the State Comptroller General's Office. Methodology: Applies the analytical method by having to examine in depth the internal characteristics of the object or phenomenon of study, define and adequately describe the problems that were studied and analyzed, in order to obtain the expected results. Contributions: This article aims to demonstrate that, through effective practices of prior control in public contracting with the participation of the Comptroller General of the Nation, acts of corruption that, at present, has become fashionable, can be avoided directly affecting the treasury national.
\end{abstract}

Keywords: public procurement, prior control, surety, corruption.

\section{Resumen}

En el Ecuador en los últimos años, se viene observando el cometimiento de actos de corrupción especialmente, en las contrataciones públicas que, en su mayoría se encuentran con sobreprecios, razón por la cual se plantea como Objetivos: Participar en

\footnotetext{
${ }^{1}$ Universidad Nacional de Chimborazo, Facultad de Ciencias Políticas y Administrativas, Carrera de Contabilidad y Auditoría, gemapaula@unach.edu.ec

${ }^{2}$ Universidad Nacional de Chimborazo, Facultad de Ciencias Políticas y Administrativas, Carrera de Contabilidad y Auditoría, dgallegos@unach.edu.ec
} 
los exámenes especiales de contratación de obra cierta, mediante el proceso de Licitación, habiendo confirmado que hubo sobreprecio, contrato que fue direccionado desde las autoridades y miembros del Comité de Contratación, utilizando horarios fuera de tiempo de atención al público; y el segundo, por Capacitación a pequeños y medianos agricultores, efectuado mediante Concurso Público de Ofertas de menor cuantía, demostrando el cumpliendo de las políticas de eficiencia, efectividad y economía, establecidas por la Contraloría General del Estado. Metodología: Aplica el método analítico por tener que, examinar en profundidad las características internas del objeto o fenómeno de estudio, definir y describir adecuadamente los problemas que fueron estudiados y analizados, para llegar a obtener los resultados esperados. Aportes: El presente artículo pretende demostrar que, mediante prácticas efectivas de control previo en las contrataciones públicas con la participación de la Contraloría General de la Nación, se puede evitar actos de corrupciones que, en la actualidad se ha vuelto de moda afectando directamente al erario nacional.

Palabras claves: contratación pública, control previo, caución, corrupción.

\section{Introducción}

La presente investigación, se la realizó debido a la presencia de la corrupción en diferentes países del mundo; y en particular, en la República del Ecuador, existiendo sobreprecios en las transacciones de bienes y servicios; razón por la cual, tuvimos la oportunidad de examinar contratos por ejecución de una obra cierta y capacitación, dándonos como resultados actos de corrupción en el uno; y en otro, un normal cumplimiento de las disposiciones legales; todo esto, por falta de intervención de la Contraloría General del Estado en la aplicación efectiva del Control Previo, la conformación adecuada de Comités de Contratación y sus reglamentos; y, falta de presentación debidamente respaldadas de cauciones por parte de los miembros integrantes de los comités; todo, en busca de garantizar el correcto cumplimiento de procesos contractuales.

\section{Marco Teórico}

Ley de contratación pública.- "Capítulo II De los procedimientos precontractuales.Art. 4.- Procedimientos comunes.- Para la adquisición de bienes muebles, la ejecución de obra, prestación de servicios no regulados por la Ley de Consultoría, el arrendamiento mercantil, se observarán los procedimientos de conformidad con la cuantía del correspondiente presupuesto referencial: a) Licitación: Si la cuantía supera el valor que resulte de multiplicar el coeficiente 0,00004 por el monto del presupuesto inicial del Estado del correspondiente ejercicio económico; y, b) Concurso Público de Ofertas: Si la cuantía no excede del valor al que se refiere el literal anterior, pero supera el valor que resulte de multiplicar el coeficiente 0,00002 por el monto del presupuesto inicial del Estado del correspondiente ejercicio económico...La adquisición de bienes muebles, la ejecución de obra, y la prestación de servicios no regulados por la Ley de Consultoría, 
cuya cuantía sea inferior al valor que resulte de multiplicar el coeficiente 0,00002 previsto en el literal b) por el monto del presupuesto inicial del Estado del correspondiente ejercicio económico, no se sujetarán a los procedimientos precontractuales previstos en esta ley, pero para celebrar los contratos respectivos se observarán las normas reglamentarias pertinentes que para el efecto dictará cada uno de los organismos contratantes...En el caso de arrendamiento mercantil con opción de compra, se considerará como cuantía el precio del mercado de los bienes objeto de arriendo a la fecha de iniciación del procedimiento precontractual” (Estado Ecuatoriano, 2001, pág. 2).

Ley de contratación pública. - "Art. 5.- Procedimientos especiales. - Se someterán a los procedimientos especiales contemplados en esta misma ley, las contrataciones relativas a la adquisición de bienes inmuebles, las de arrendamiento de bienes muebles e inmuebles, las que se efectúen con recursos provenientes de préstamos concedidos por organismos multilaterales de los cuales el Ecuador sea miembro" (Estado Ecuatoriano, 2001).

Ley de contratación pública. - "Art. 6.- Excepciones. - Se exceptúan de los procedimientos precontractuales los siguientes contratos: a) Los que sean necesarios para superar emergencias graves que provengan de fuerza mayor o caso fortuito y que solo sirvan para solucionar los daños que aquellas hayan producido o prevenir los que puedan suscitar; b) Los requeridos para la ejecución de proyectos prioritarios que se celebren en aplicación de convenios con Gobiernos extranjeros que ofrezcan financiamiento en términos concesionarios y ventajosos para el país, o por organismos multilaterales de los cuales el Ecuador sea miembro, en este caso se estará a lo dispuesto en el artículo 53 de esta ley. Los requeridos para la ejecución de obras, prestación de servicios o adquisición de bienes que se celebren con financiamiento de créditos otorgados por el sector privado, en base a un pedido formal del Gobierno del Ecuador. c) Los calificados por el Presidente de la República como necesarios para la seguridad interna y externa del Estado, y cuya ejecución esté a cargo de las Fuerzas Armadas o de la Policía Nacional; d) Los de permuta, aun cuando el valor de uno de los bienes exceda hasta en un veinte por ciento del asignado al otro y el correspondiente propietario se obligue al pago de la diferencia; e) Aquellos cuyo objeto sea la ejecución de una obra artística, literaria o científica; f) Los de transporte de correo internacional, que se rigen por los convenios de la Unión Postal Universal, Unión Postal de las Américas y España; y, los de transporte interno de correo, que se regirán por las disposiciones legales y reglamentarias dictadas para el efecto; g) Aquellos cuyo proceso precontractual establecido en esta ley fuere declarado desierto después de la reapertura y fueren calificados como urgentes por el Presidente de la República, salvo lo previsto en el literal d) del artículo 29 de esta ley; h) Los de adquisición de repuestos o accesorios que se requieran para el mantenimiento de equipos y maquinarias a cargo de las instituciones públicas; i) Los que, por leyes especiales, estén exonerados de licitación y concurso público de ofertas; j) Los de adquisición de bienes respecto a los cuales se comprobaren que son únicos en el mercado, que tienen un solo proveedor o que implican la utilización de patentes o marcas exclusivas y que no admiten alternativas de solución; k) Los que celebren el Estado con entidades del sector público, 
éstas entre sí, o aquel o éstas con empresas cuyo capital suscrito pertenezca, por lo menos en las dos terceras partes, a entidades de derecho público o de derecho privado con finalidad social o pública. La máxima autoridad del Ministerio o los representantes legales de la entidad serán responsables por la celebración de los contratos a que se refiere este artículo, tanto en la observancia de los requisitos legales para su perfeccionamiento y ejecución, incluidos los previstos en el artículo 60 de esta ley, como en la determinación de la causa para la celebración del contrato sin licitación ni concurso, de conformidad con los literales que anteceden. Cuidará que el contratista tenga solvencia legal, técnica y económica, rinda garantías suficientes, de acuerdo con esta ley, así como que el contrato convenga a los intereses nacionales e institucionales" (Estado Ecuatoriano, 2001, pág. 3).

Corrupción. - El término "corrupción" se ha instalado en el ámbito académico, en la prensa y en la opinión pública en general, pero existe un alto grado de ambigüedad en cuanto a su significado. Pese a lo extendido del uso, el significado del término varía de un contexto socio cultural a otro y, en muchos casos, un uso indiscriminado dificulta una definición única. Para precisar el significado de corrupción debemos comenzar por la cuestión etimológica del término, que proviene del latín corruptio que resulta de com (junto) y rumpere (romper). Supone un acto que altera el estado de las cosas, y ese es el sentido aristotélico de la corrupción: la desnaturalización de un ente cuando éste actúa no regido por el fin que le impone su naturaleza, sino en función de un fin ajeno. La versión vigente del Diccionario de la Real Academia Española precisa: "acción y efecto de corromper o corromperse", es decir, alterar y trastocar la forma de algo, en otras acepciones agrega "Estragar, viciar, pervertir" o "Sobornar a alguien con dádivas o de otra manera", y en una acepción más específica incorporada a partir de 2001 dice: "En las organizaciones, especialmente las públicas, práctica consistente en la utilización de las funciones y medios de aquellas en provecho, económico o de otra índole, de sus gestores”. Esta última acepción muestra una evolución hacia el significado más amplio de corrupción, pero, al contar con una definición única se dificulta si se considera que son muchas los significados del término, ya que ante todo constituye una categoría cultural que forma parte de los discursos jurídico, económico y social, pero también del lenguaje corriente. Los estudios que provienen del ámbito jurídico conciben la corrupción en el plano político, al considerar el uso del poder para beneficio privado o de un grupo o clase connota el quebrantamiento de normas jurídicas. Las posiciones formalistas o legalistas representan una aproximación sociopolítica al fenómeno y por lo tanto el significado del término necesariamente refiere que las conductas corruptas implican violación de preceptos legales. La función pública como bien jurídico colectivo interesa desde el punto de vista de su correcto desempeño y puede ser afectada en distintos aspectos, según la acción concreta que la lesiona o pone en riesgo; puede, además, ser afectada en compañía de otros bienes jurídicos individuales e institucionales que resultan consiguientemente lesionados o puestos en peligro" (Szczaranski Cerda, 2011, pág. 178)

Delitos de actos de corrupción. - "Peculado: Es el acto ilegal ejecutado por un servidor público quien se apropia o hace abuso voluntario de dinero u otra cosa mueble e inmueble que pertenece a la administración pública en beneficio propio o de terceros. Este delito 
está tipificado en el Art. 278 del Código Orgánico Integral Penal (COIP); Concusión: Es el acto ilegal ejecutado por una o un servidor público quien, en uso de su cargo, exige la entrega de una contribución, gratificación, sueldo, que no le corresponde por las funciones que realiza. Este delito está tipificado en el Art. 281 del Código Orgánico Integral Penal (COIP); Enriquecimiento ilícito: Es el acto ilegal por el cual una o un servidor público ha obtenido para sí o para terceros un incremento patrimonial injustificado a su nombre o mediante persona interpuesta, producto de su cargo o función. Este delito está tipificado en el Art. 279 del Código Orgánico Integral Penal (COIP); Cohecho: Es el acto ilegal por el cual una o un servidor público acepta y recibe por sí o por interpuesta persona, cualquier tipo de beneficio económico indebido, sea para hacer, omitir, agilitar, retardar o condicionar cuestiones relativas a sus funciones. Este delito está tipificado en el Art. 280 del Código Orgánico Integral Penal (COIP); Tráfico de influencias: Consiste en utilizar la influencia personal o jerárquica en ámbitos de gobierno, a través de conexiones con personas, con el $\mathrm{n}$ de obtener favores o tratamiento preferencial o resolución favorable a sus intereses o de terceros. Este delito está tipificado en el Art. 285 del Código Orgánico Integral Penal (COIP); Nepotismo: Acto ilegal ejecutado por una autoridad nominadora al designar, nombrar, posesionar o contratar en la misma entidad pública a sus parientes comprendidos hasta el cuarto grado de consanguinidad y segundo de anidad, a su cónyuge o con quien mantenga unión de hecho. Prohibición legal constante en el Art. 6 de la Ley Orgánica del Servicio Púbico (LOSEP)".

Control Interno. - El control interno será responsabilidad de cada institución del Estado y de las personas jurídicas de derecho privado que dispongan de recursos públicos y tendrá como finalidad crear las condiciones para el ejercicio del control. El control interno es un proceso integral aplicado por la máxima autoridad, la dirección y el personal de cada entidad, que proporciona seguridad razonable para el logro de los objetivos institucionales y la protección de los recursos públicos. Constituyen componentes del control interno el ambiente de control, la evaluación de riesgos, las actividades de control, los sistemas de información y comunicación y el seguimiento. El control interno está orientado a cumplir con el ordenamiento jurídico, técnico y administrativo, promover eficiencia y eficacia de las operaciones de la entidad y garantizar la confiabilidad y oportunidad de la información, así como la adopción de medidas oportunas para corregir las deficiencias de control. El control interno de las entidades, organismo del sector público y personas jurídicas de derecho privado que dispongan de recursos públicos para alcanzar la misión institucional, deberá contribuir al cumplimiento de los siguientes objetivos: - Promover la eficiencia, eficacia y economía de las operaciones bajo principios éticos y de transparencia. - Garantizar la confiabilidad, integridad y oportunidad de la información. - Cumplir con las disposiciones legales y la normativa de la entidad para otorgar bienes y servicios públicos de calidad. - Proteger y conservar el patrimonio público contra pérdida, despilfarro, uso indebido, irregularidad o acto ilegal. El diseño, establecimiento, mantenimiento, funcionamiento, perfeccionamiento, y evaluación del control interno es responsabilidad de la máxima autoridad, de los directivos y demás servidoras y servidores de la entidad, de acuerdo con sus competencias. Los directivos, en el cumplimiento de su responsabilidad, pondrán especial cuidado en áreas de mayor 
importancia por su materialidad y por el riesgo e impacto en la consecución de los fines institucionales. Las servidoras y servidores de la entidad, son responsables de realizar las acciones y atender los requerimientos para el diseño, implantación, operación y fortalecimiento de los componentes del control interno de manera oportuna, sustentados en la normativa legal y técnica vigente y con el apoyo de la auditoría interna como ente asesor y de consulta. (Contraloría General del Estado Ecuador, 2014, págs. 3,4)

\section{Metodología}

La metodología aplicada en la presente investigación, es analítica, debido a que tiene la finalidad de examinar en profundidad las características internas del objeto o fenómeno de estudio, por lo que, para lograr este propósito, se necesitó definir y describir adecuadamente los problemas que fueron estudiados y analizados; la investigación descriptiva fue de gran ayuda para efectuar los análisis correspondientes de conformidad a las siguientes características: conocimiento detallado de los diferentes objetos que se investigaron; el objetivo de nuestro estudio, fue llegar a conocer los aspectos esenciales y las relaciones fundamentales que se manifestaron en actos de corrupción o no en las contrataciones de bienes y servicios por parte de funcionarios del Estado, cuáles fueron sus causas y efectos; $y$, todo el tratamiento que se dio para lograr los resultados esperados de esta investigación.

\section{Resultados}

La presente investigación fue realizada mediante el método analítico, con enfoque mixto cualitativo y cuantitativo, debido a que fue necesaria la revisión de documentos archivados relacionados a contrataciones de obras civiles y servicios en organismos del Estado.

Por lo tanto, para llevar a cabo la presente investigación, fue necesario concurrir a algunas dependencias del sector público, (que en este estudio, se guarda reserva en cuanto a su identificación y fechas de sus ejecuciones) habiendo efectuado la correspondiente solicitud para que se nos facilite la entrega de información documentada, con el objeto de efectuar esta investigación de carácter científico, la misma que conllevaba a realizar un análisis relacionado a los procesos efectuados en la adquisición de bienes y servicios, confrontándolos con la legislación del Estado Ecuatoriano.

Esta actividad dio lugar a ir relacionando los hechos, con disposiciones legales vigentes y de esta manera, poder emitir criterios lógicos, con la finalidad de esclarecer reservadamente, si existieron o no irregularidades, en los sistemas previos a la contratación y posterior a los contratos suscritos, todo esto debido a que en la actualidad han existido una serie de denuncias sobre actos de corrupción por parte de funcionarios de los Gobiernos Central y Seccionales de la República del Ecuador.

Montos de Contratación. - Para efectuar nuestra investigación; y poder determinar, a qué proceso se sometieron las adquisiciones objeto de del estudio; fue necesario, determinar los montos a que se debieron sujetar dichas transacciones de conformidad a la 
Ley de Contratación Pública y al Presupuesto General del Estado Ecuatoriano, para el ejercicio económico 2019, en que se ejecutaron los contratos:

\begin{tabular}{|c|c|c|}
\hline \multicolumn{3}{|c|}{ Cuadro No 1} \\
\hline \multicolumn{3}{|c|}{ MONTOS DE CONTRATACIÓN 2019} \\
\hline \multicolumn{3}{|c|}{ Presupuesto Inicial del Estado: $\$ 35.529^{\prime} 394.461,72$} \\
\hline CONTRATACIÓN & PROCEDIMIENTOS & MONTOS DE CONTRATACIÓN \\
\hline \multirow{3}{*}{$\begin{array}{c}\text { Bienes y Servicios } \\
\text { Normalizados }\end{array}$} & Catálogo Electrónico & Sin límite de monto \\
\hline & Subasta Inversa Electrónica & Mayor $a \$ 7.105,88$ \\
\hline & Ínfima Cuantía & Inferior $a \$ 7.105,88$ \\
\hline \multirow{3}{*}{$\begin{array}{l}\text { Bienes y Servicios } \\
\text { No Normalizados }\end{array}$} & Menor Cuantía & Inferior a $\$ 71.058,79$ \\
\hline & Cotización & Entre $\$ 71.058 .79$ y $\$ 532.940,92$ \\
\hline & Licitación & Mayor $a \$ 532.940,92$ \\
\hline \multirow{4}{*}{ Obras } & Menor Cuantía & Inferior $a \$ 248.705,76$ \\
\hline & Cotización & Entre $\$ 248.705,76$ y $\$ 1.065 .881,83$ \\
\hline & Licitación & Mayor $a \$ 1.065 .881,83$ \\
\hline & Contratación Integral por Precio Fijo & Mayor a $\$ 248.705,76$ \\
\hline \multirow{3}{*}{ Consultoría } & Contratación Directa & Menor o igual a $\$ 71.058,79$ \\
\hline & Lista Corta & Mayor a $\$ 71.058,79$ y menor $a \$ 532.940,92$ \\
\hline & Concurso Público & Mayor o igual $a \$ 532.940,92$ \\
\hline
\end{tabular}

Con estos antecedentes, escogimos dos casos de contrataciones uno de Obras con procedimiento de Licitación por Pavimentación de un tramo de carretera secundaria por un valor de \$982.800,00, por; y otro, por Servicios No Normalizados con procedimiento de Menor Cuantía, por Capacitación especializada en tecnología agropecuaria por un monto de $\$ 42.310,00$.

Proceso de Contratación. - Para verificar los procesos de contrataciones en referencia, las entidades del sector público interesadas, habían ingresado los datos exigidos y obligatorios del "Socop" Sistema Oficial de Contratación Pública establecido por el "Sercop" Servicio Nacional de Contratación Pública, de conformidad a los montos relacionados a licitación y contratación reglamentada.

En cumplimiento con la Ley de Contratación Pública, se detalla la siguiente Información relevante.- Para efectos de publicidad de los procedimientos de contratación en el Portal www.compraspublicas.gov.ec se entendió como información relevante la siguiente: 1. Convocatoria; 2. Pliegos; 3. Proveedores invitados; 4. Preguntas y respuestas de los procedimientos de contratación; 5. Ofertas presentadas por los oferentes, con excepción de la información calificada como confidencial por la entidad contratante conforme a los pliegos; 6. Resolución de adjudicación; 7. Contrato suscrito, con excepción de la información calificada como confidencial por la entidad contratante conforme a los pliegos; 8. Contratos complementarios, de haberse suscrito; 9. Ordenes de cambio, de haberse emitido; 10. Cronograma de ejecución de actividades contractuales; 11. Cronograma de pagos; y, 12. Actas de entrega recepción, o actos administrativos 
relacionados con la terminación del contrato. 12-A.- En general, cualquier otro documento de las fases preparatoria, pre contractual, contractual, de ejecución o de evaluación que defina el SERCOP mediante resolución para la publicidad del ciclo transaccional de la contratación pública.

Contrato por Obra mediante Licitación.- Habiendo comprobado los pasos que han seguido en la contratación de la obra cierta, mediante el sistema de licitación pública que es un procedimiento administrativo por el cual el GAD invitó a los interesados a que, sujetándose a las bases fijadas en el pliego de condiciones, formulen propuestas de las cuales se había seleccionado y aceptado la adjudicación a la más ventajosa, o conveniente, cuyas etapas fueron las siguientes: 1. Convocatoria, 2. Junta de aclaraciones, 3. Integración de propuestas, 4. Presentación de propuestas; y, 5. Evaluación cualitativa de proposiciones. Para su adjudicación definitiva duró alrededor de dos meses, debido al análisis de la propuesta técnica, documento en el que se plasmó de forma detalla la estrategia y desarrollo para dar solución al problema propuesto.

De igual manera, se pudo constatar la información entregada al GAD por parte de la empresa adjudicada, como: diseños, planos, memorias, certificado de inscripción vigente en el registro nacional de proveedores, declaración juramentada y notariada, Registro Único del Contribuyente, Registro Único de Proveedor, certificados de experiencia que acredite haber cumplido otros compromisos, garantías por el anticipo y cumplimiento del contrato, entre otros.

Acompañados con un ingeniero civil, especializado en la construcción de vías, se procedió a verificar el cumplimiento relacionado a la pavimentación con capa base de hormigón asfáltico de un tramo de vía secundaria al interior de la provincia, de conformidad a la documentación anexa al contrato, los mismos que habían sido debidamente suscritos y registrados de acuerdo a la Ley de Contratación, por un monto de $\$ 982.800,00$.

El análisis efectuado del proceso de contratación, desde el origen de la necesidad hasta la suscripción del contrato, de manera selectiva sobre los más significativos; determinó algunas deficiencias en el mismo, en especial, en las convocatorias, invitaciones o concursos, análisis de invitaciones o concursos, análisis de precios unitarios, debido a que, si lo ofertado es igual a lo contratado y ejecutado, posibles nexos de consanguinidad o afinidad con autoridades del GAD, seriedad de ofertas y garantías para el cumplimiento; observancia de disposiciones y reglamentos aplicables.

Se solicitó, asimismo, al contratista confirmaciones de la información mencionada anteriormente, se realizaron ciertos comentarios desde el punto de vista de la contratación, para ir verificando algunos supuestos; se mantuvo asimismo reuniones con algunos funcionarios y miembros de las comunidades del sector de la obra cierta, a fin de lograr obtener declaraciones testimoniales sobre la obra ejecutada y de esta manera lograr obtener si existen o no denuncias sobre el tema. 
También se pudo determinar, en base a la aplicación de los procedimientos anteriores, posibles perjuicios cuantitativos, diferencias en los pagos realizados, anticipos no devengados, plazos vencidos y multas no cobradas; sobre los pagos efectuados al contratista, se solicitaron los originales o las copias certificadas del anverso y reverso de los cheques girados y se pueda determinar su destino final de los valores. Esta labor se la pudo ejecutar con la debida autorización del Director de la Contraloría General del Estado Sectorial, por dar la importancia del caso para conocer por terceros la posibilidad de la existencia de responsabilidad penal, debiendo a la final haberse comprobado que hubo sobreprecio en un $30 \%$ del valor total del contrato, confirmado por la Contraloría, debido a que la adjudicación del contrato fue direccionada hacia la empresa interesada por la Autoridad del GAD, así como la adjudicación mediante el sistema de compras públicas, fue ejecutada en horas de la madrugada o sea fuera de las horas laborables.

Contrato por Servicio No Normalizado.- En el segundo caso, relacionado a un contrato por servicios de capacitación, cuya invitación de acuerdo a las políticas establecidas en el MAG, se llevó a cabo mediante el modelo de pliegos de subasta inversa electrónica, en función de la resolución INCOP a nombre del MAG Provincial, se describe el código del proceso; $y$, los datos correspondientes a la convocatoria, objeto del contrato, condiciones generales, condiciones específicas, en este caso servicios en cuanto a las obligaciones del contratista y contratante, la forma de presentar la oferta técnica, anexos de las condiciones específicas, con las especificaciones técnicas, el presupuesto referencial, el proyecto del contrato, anexando los formatos 1. Modelo de carta de presentación y compromiso, 2. Datos generales del oferente, 3. Modelo de carta de confidencialidad (de ser pertinente), 4 . Soporte técnico, entre otros.

Previa la contratación, se observó que habían entregado una circular para dar a conocer los parámetros exigidos en el programa de capacitación: Experiencia en capacitación con microempresarios rurales y urbanos del sector rural agropecuario y microempresarial, conocimiento en metodología andragógica, experiencia en programas tecno productivos agropecuarios, experiencia en programas de asociatividad crediticia rural, experiencia en alianzas estratégicas con entidades de similar actividad; y, contar con una base de datos actualizada del sector agropecuario.

Los Operadores de Capacitación pueden ser personas naturales o jurídicas, pública, privada o mixta, con o sin fines de lucro, con capacidad legal para obligarse, que tengan entre sus objetivos o fines, atribuciones, funciones o competencias, la ejecución de actividades de capacitación y formación profesional, es decir que esté habilitado para ello y que aseguren y/o evidencien la calidad, pertinencia y especialización de sus servicios, a través del cumplimiento de los requisitos establecidos por el "CNCF" Consejo Nacional de Capacitación y Formación Profesional.

La Operadora de Capacitación a la que fue adjudicada el contrato, había cumplido con todos y cada uno de los requisitos, debido a que disponía de los certificados de calificación como tal del "SECAP" Servicio de Capacitación Profesional, "CNCF" Consejo Nacional de Capacitación y Formación Profesional e "INCCA "Instituto 
Nacional de Capacitación Campesina, contando con profesionales experimentados en las especialidades de Ingeniería en Zootecnia, Agronomía y Veterinaria.

La Operadora, había demostrado con eficiencia, el plan y cronograma de cumplimiento de capacitaciones en diferentes temas, prácticas - teóricas a miembros de organizaciones campesinas de los cantones Guano, Penipe, Riobamba, Chambo, Colta, Guamote, Alauí, Chunchi, Pallatanga y Cumandá de la provincia de Chimborazo, de acuerdo a los siguientes temas:

\section{Cuadro No 2}

\begin{tabular}{|c|c|}
\hline \multicolumn{2}{|r|}{ PARA PEQUEÑOS AGRICULTORES } \\
\hline DIRIGIDO A & $\begin{array}{l}\text { ASOCIACIADOS, COMUNEROS, MICROEMPRESARIOS Y } \\
\text { ESTUDIANTES }\end{array}$ \\
\hline METODOLOGIA & $\begin{array}{l}\text { “APRENDER HACIENDO” } \\
\text { Talleres modulares, especializados en conformación de } \\
\text { grupos de trabajo, con aplicación en formación de adultos } \\
\text { (andragógicos), que supone la elevación del pensamiento } \\
\text { crítico y la percepción de su utilidad práctica. } \\
\text { Se utilizará modelos de trabajo prácticos y laboratorio de } \\
\text { campo, los que serán aplicados y expuestos por los } \\
\text { participantes para su evaluación en el transcurso del taller. }\end{array}$ \\
\hline REQUERIMIENTOS & $\begin{array}{l}\text { PERSONAL.- } \\
\text { FACILITADOR - INTRUCTOR, Técnico, especializado y } \\
\text { experimentado para llevar a cabo el Curso - Taller } \\
\text { COORDINADOR DE LA INSTITUCION CONTRATANTE } \\
\text { RESPONSABLE DE: Convocar y confirmar la asistencia de } \\
\text { participantes, presenciar y evaluar el evento } \\
\text { INFRAESTRUCTURA Y EQUIPO. - } \\
\text { Aula con disponibilidad de energía eléctrica, mesas o } \\
\text { pupitres para cada uno de los participantes, pizarra, } \\
\text { papelógrafo, computador y proyector } \\
\text { MATERIALES. - } \\
\text { Pliegos papel periódico, másquin, marcadores para pizarra } \\
\text { y permanentes, borrador, cuadernos, esferográficos y } \\
\text { manuales y folletería (copias de memorias del curso) }\end{array}$ \\
\hline TIEMPO DE DURACION & $\begin{array}{l}\text { Cinco horas diarias y dependiendo del evento uno hasta } \\
\text { tres días }\end{array}$ \\
\hline VALOR DEL MODULO & A CONVENIR CON LA INSTITUCION INTERESADA \\
\hline PARTICIPANTES & RECOMENDABLE $20 \quad$ ACEPTABLE 30 \\
\hline $\begin{array}{c}\text { NOMINA } \\
\text { INSTRUCTORES }\end{array}$ & $\begin{array}{l}\text { Se anexa copias de hojas de vida de instructores - } \\
\text { facilitadores }\end{array}$ \\
\hline
\end{tabular}

Fuente: MAG. Oferta Plan de Capacitación RB. Asesoría y Capacitación 2019 


\section{Cuadro No 3}

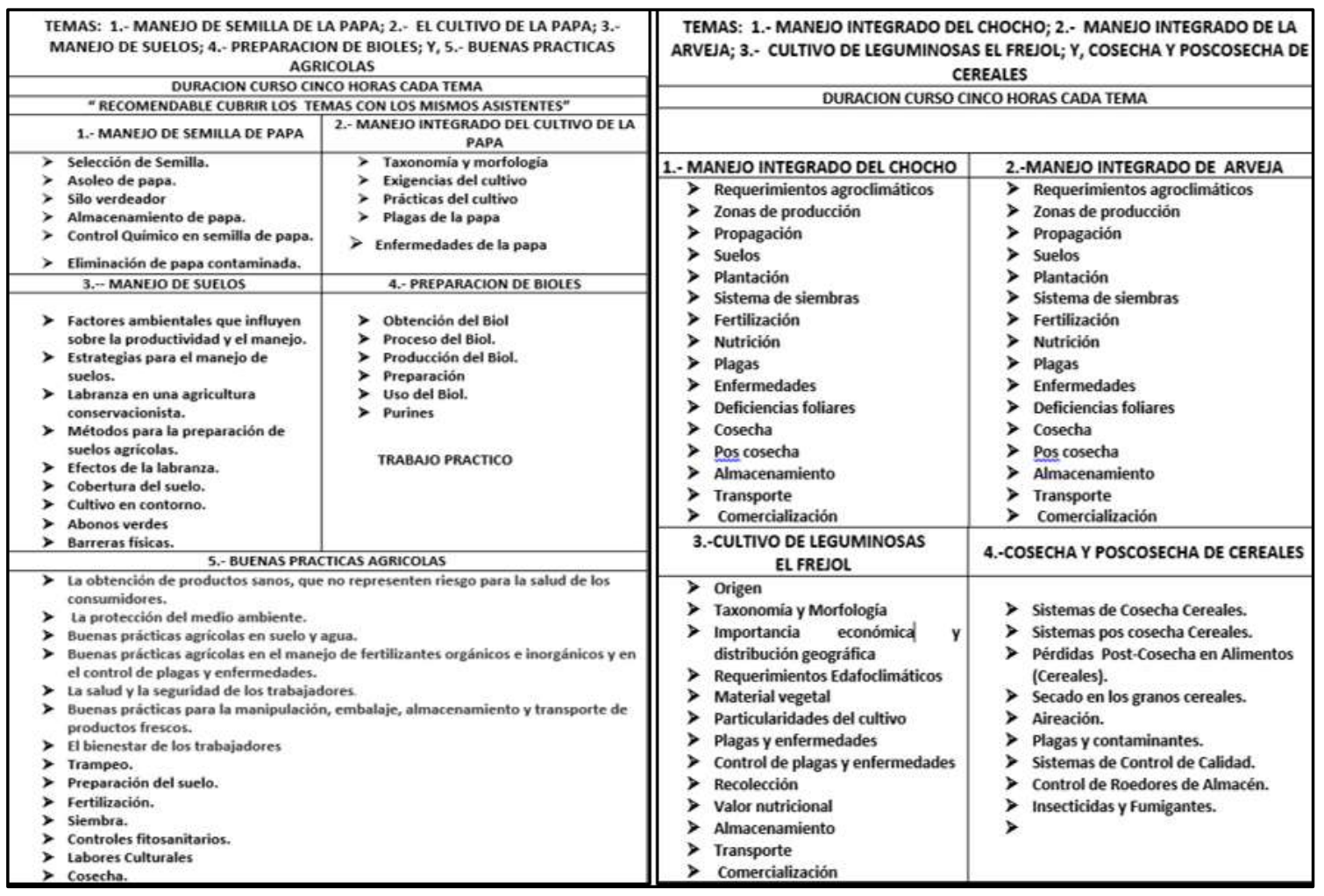

Fuente: MAG. Oferta Plan de Capacitación RB. Asesoría y Capacitación 2019

\section{Cuadro No 4}




\begin{tabular}{|c|c|c|c|}
\hline \multirow{2}{*}{\multicolumn{2}{|c|}{$\begin{array}{l}\text { TEMAS GANADERIA BOVINA.- 1.- MANEJO: CRIANZA DE TERNEROS Y } \\
\text { AUMENTACION; 2.- SANIDAD: ENFERMEDADES VIRALES, BACTERIANAS, } \\
\text { METABOUCAS Y PARASITARIAS; 3.- SELCCCOON Y REPRODUCCON BOVINA; } Y \text {, } \\
\text { 4.- MANEIO DE PASTOS Y FORRAIES }\end{array}$}} & \multirow{2}{*}{\multicolumn{2}{|c|}{$\begin{array}{l}\text { ENFERMEDADES VIRALES, BACTERIANAS, METABOLICAS Y PARASITARIAS; 3.- } \\
\text { SELECCIÓN Y REPRODUCCION PORCINA; } Y, 4 \text {,-ALIMENTACION.DURACION CURSO } \\
\text { CINCO HORAS CADA TEMA } \\
\text { "RECOMENDABLE CUBRIR LOS CUATRO TEMAS CON LOS MISMOS ASISTENTES" }\end{array}$}} \\
\hline & & & \\
\hline $\begin{array}{r}\text { DURACION CURSO CIN } \\
\text { "RECOMENDABIE CUBRIR LOS CUATR }\end{array}$ & $\begin{array}{l}\text { HORAS CADA TEMA } \\
\text { MAS CON LOS MISMOS ASISTENTES" }\end{array}$ & 1.- EXPLOTACION PORCINA & 2. SANIDAD \\
\hline 1.- CRLANEA DE TERNEROS & 2-SANIDAD & $\begin{array}{l}\text { Introducción y recomendaciones } \\
\text { generales }\end{array}$ & $\begin{array}{l}>\text { Enfermedades más frecuentes en el } \\
\text { Eanado porcino }\end{array}$ \\
\hline \multirow[t]{3}{*}{ 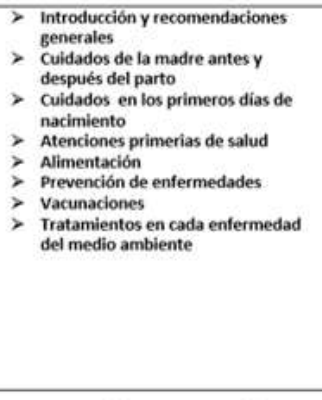 } & \multirow{3}{*}{ 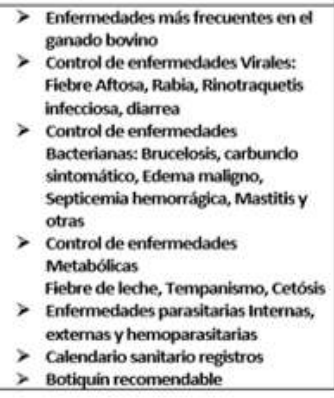 } & $\begin{array}{l}\text { Manejo intensivo y semiestabulado } \\
\text { Cuidados de la madre antes y } \\
\text { después del parto } \\
\text { Cuidado de lechones } \\
>\text { Pie de cría } \\
\text { Cuidados en los primeros dias de } \\
\text { nacimiento } \\
\text { Atenciones primerias de salud } \\
\text { Alimentación } \\
\text { Prevención de enfermedades } \\
>\text { Vacunaciones } \\
\text { Tratamientos en cada enfermedad } \\
\text { del medio ambiente }\end{array}$ & $\begin{array}{l}\text { Control de enfermedades Virales: } \\
\text { Control de enfermedades } \\
\text { Bacterianas: Control de } \\
\text { enfermodades Metabólicas } \\
>\text { Control de enfermedades } \\
\text { parasitarias internas, externas y } \\
\text { hemoparasitarias } \\
>\text { Calendario sanitario reeistros } \\
>\text { Botiquin recomendable }\end{array}$ \\
\hline & & 3.-SELECCOÓN Y REPRODUCAÓN & 4. AUMENTACOON: PASTOS Y BALANCEADO \\
\hline & & Aspectos limitantes de la producción & Mejoramiento praderas naturales \\
\hline 3.- SELECCOÓN Y REPROOUCCOÓN & 4-MANEO DE PASTOS YFORRAES & $\begin{array}{l}\text { de cerdos } \\
\text { Aspectos generales para una }\end{array}$ & Renovación dep $\mathrm{P}$ \\
\hline $\begin{array}{l}\text { Identificación y registros } \\
\text { Clasificación por edades } \\
\text { Razas y propósitos } \\
\text { Monta natural } \\
\text { inseminación artificial : (E semen, } \\
\text { anatomia reproductiva del toro, } \\
\text { anatomia reproductiva de la vaca, } \\
\text { situadón de los órganos } \\
\text { reproductivos de la vaca, recipientes } \\
\text { para el semen, manejo y } \\
\text { almacenamiento del semen } \\
\text { congelado, instrumentos para } \\
\text { inseminar, preparación para } \\
\text { inseminar, métodos de } \\
\text { inseminación }\end{array}$ & $\begin{array}{l}\text { > Mejoramiento praderas naturales } \\
\text { > Fertilizadón } \\
\text { > Renovación de potreros } \\
\text { > Mezclas forrajeras } \\
\text { > Rotación de potreros } \\
>\text { Pastoreo controlado de uso de cercas }\end{array}$ & $\begin{aligned} & \text { explotación exitosa } \\
&> \text { Principales tipos de cruzamiento } \\
&> \text { Clasificación de lechones para pie de } \\
& \text { cria } \\
&> \text { Razas recomendables y propósitos } \\
&> \text { Manejo de gestación, sintomas de } \\
& \text { celo } \\
&> \text { inseminación artificial: Control } \\
& \text { sanitario, utilización de machos } \\
& \text { mejorados, mejoramiento genético } \\
&>\text { Manejo de verracos } \\
&>\text { Manejo de lactancia } \\
&>\text { Manejo en crecimiento yengorde }\end{aligned}$ & $\begin{array}{l}\text { Mezclas forrajeras } \\
\text { Rotación de potreros } \\
\text { Pastoreo controlado de uso de cercas } \\
\text { Preparación de alimento balanceado } \\
\text { Crecimiento y engorde }\end{array}$ \\
\hline
\end{tabular}

Fuente: MAG. Oferta Plan de Capacitación RB. Asesoría y Capacitación 2019

\section{Cuadro No 5}




\begin{tabular}{|c|c|}
\hline \multicolumn{2}{|c|}{ DURACION CURSO CINCO HORAS CADA TEMA } \\
\hline \multicolumn{2}{|c|}{ “RECOMENDABLE CUBRIR LOS CUATRO TEMAS CON LOS MISMOS ASISTENTES" } \\
\hline 1.-SELECCOÓN Y REPRODUCCION OVINA & 2.- SANIDAD \\
\hline $\begin{array}{l}\text { Introducción y recomendaciones } \\
\text { generales } \\
>\text { Manejo intensivo y semiestabulado } \\
\text { Cuidados de la madre antes y } \\
\text { después del parto } \\
\text { Cuidado de corderos } \\
\text { Identificación y descarte } \\
>\text { Castración } \\
>\text { Pie de cría } \\
>\text { Cuidados en los primeros días de } \\
\text { nacimiento } \\
>\text { Atenciones primerias de salud } \\
\text { Alimentación } \\
>\text { Uso de machos mejorantes } \\
>\text { Monta natural y controlada }\end{array}$ & $\begin{array}{l}\text { Enfermedades más frecuentes en el } \\
\text { ganado ovino } \\
>\text { Control de enfermedades Virales: } \\
>\text { Control de enfermedades Bacterianas: } \\
\text { Control de enfermedades Metabólicas } \\
>\text { Control de enfermedades parasitarias } \\
\text { Internas, externas y hemoparasitarias } \\
>\text { Calendario sanitario registros } \\
>\text { Botiquín recomendable }\end{array}$ \\
\hline 3.- NUTRICION Y AUMENTACION & 4.- MANEO DE PASTOS Y FORRAIES \\
\hline $\begin{array}{l}\text { Sistema digestivo de la oveja } \\
>\text { Pastoreo } \\
>\text { Requerimientos nutricionales } \\
>\text { Mineralización } \\
>\text { Uso de concentrados alimenticios }\end{array}$ & $\begin{array}{l}\text { Mejoramiento praderas naturales } \\
\text { Fertilización } \\
\text { Renovación de potreros } \\
\text { Mezclas forrajeras } \\
\text { Rotación de potreros } \\
\text { Pastoreo controlado de uso de cercas } \\
\text { Preparación de alimento balanceado } \\
\text { Crecimiento y engorde }\end{array}$ \\
\hline
\end{tabular}

Fuente: MAG. Oferta Plan de Capacitación RB. Asesoría y Capacitación 2019

Entre otros temas desarrollados fueron: La fiebre Aftosa, Estomatitis Vesicular, Manejo del Ganado, Reproducción, Aplicación de vacunas y medicamentos, Manejo de tarjetas de registros, Parásitos internos, Peste porcina, Brucelosis, Cisticercosis, Leptospirosis, Mastitis, Neumoenteritis, Rabia, Tuberculosis, entre otras enfermedades según el sector de mayor contagio o enfermedades ganaderas.

Se demostraron los registros de asistencia debidamente firmados y con huellas digitales de los asistentes, así como fotos y videos de cada una de las exposiciones, todo bajo control del Administrador de la Institución contratante y del Coordinador de la Empresa Contratista.

Se confirma que el contrato por el servicio de capacitación, desde su adjudicación y desarrollo, fue debidamente manejado con eficiencia, eficacia y efectividad; y más que todo, sin encontrar irregularidad alguna en su costo y pagos aplicados al Presupuesto aprobado de la Institución del Estado.

El Control Previo para evitar corrupciones. - Práctica que es obligatoria previamente a la autorización para la ejecución de un gasto, las personas que conforman el Comité de Adquisiciones de Bienes y Servicios de cualquier institución del Estado, deben verificar previamente que: "1. La operación financiera esté directamente relacionada con la misión de la entidad y con los programas, proyectos y actividades aprobados en los planes operativos anuales y presupuestos 2. La operación financiera reúna los requisitos legales 
pertinentes y necesarios para llevarla a cabo, que no existan restricciones legales sobre la misma. 3. Exista la partida presupuestaria con la disponibilidad suficiente de fondos no comprometidos a fin de evitar desviaciones financieras y presupuestarias" (Contraloría General del Estado, 2014, pág. 12).

Apartándonos un poco de tantas disposiciones; sean éstas, leyes, códigos, reglamentos, acuerdos, etc. con las experiencias adquiridas conforme al desarrollo de esta investigación, es necesario recurrir también a algunas disposiciones que anteriormente a los años 90s existieron y que las han dejado de lado; y es necesario y razonable se las tome en cuenta; asimismo, como me permito recomendar para mejorar los trámites de las adquisiciones de bienes y servicios evitando la corrupción; y que consideramos, las siguientes:

- Control Previo por la Contraloría General del Estado. - Toda adquisición superior a la base establecida en el monto mínimo para contratación por licitación o sea sobre el \$1.065.881,83, deberá autorizar su conformidad en los procesos por parte de la Contraloría General del Estado.

- Caución o Garantía. - Según el Acuerdo 015-cg-2017 de la Contraloría General del Estado Comprende, la presentación de una garantía para responder por los actos de responsabilidad en la gestión que tenga un funcionario público durante su permanencia; y más aún, sobre las decisiones en la intervención de gastos por adquisiciones de bienes y servicios; garantía que puede ser mediante un seguro o hipoteca de un inmueble a favor del Estado; los gastos de trámites deben ser cubiertos por los empleados y no por el Estado.

- Obligados a presentar Caución. - Se debe obligar a presentar caución especialmente los funcionarios que intervienen directamente en la adjudicación, administración, pagos, registros de contratos por compra de bienes y servicios.

- Cálculo para el monto de la Caución. - El cálculo del monto de la caución será cubrir el 50\% del valor básico establecido para contratos de obras o adquisiciones de bienes o servicios establecido en los Montos de Contratación por Licitación, por parte de los miembros que conforman el Comité de Adquisiciones de Bienes y Servicios, a excepción de la persona que cumple funciones en la Secretaría, en este caso por el año 2019 que supera el \$1.065.881,83; por lo tanto correspondería al valor aproximado de $\$ 532.000,00$, que será respaldado de la siguiente forma por ejemplo máxima autoridad $\$ 200.000,00$ y la diferencia entre los otros miembros, a excepción de la persona que cumple funciones en la Secretaría, dando lugar a garantizar el buen uso de los fondos públicos.

- Comité de Adquisición de Bienes y Servicios. - Todas las dependencias del Estado, obligatoriamente deben contar con un Comité de Adquisiciones de Bienes y Servicios, así como del correspondiente Reglamento. El Reglamento de Adquisición de Bienes y Servicios, debe ser concreto y entendible, evitando repetir los códigos, leyes y disposiciones, debido a que, por esta razón, muchos de sus integrantes desconocen la responsabilidad que asumen en su intervención, por lo cual conscientes o inconscientes cometen corrupciones; debiendo ser tomado 
como uno de sus artículos que, por la violación de la legislación contractual, serán sometidos a ser acusados de delitos de actos de corrupción.

El Comité de Adquisiciones de Bienes y Servicios, estará conformado por: La Máxima Autoridad de la entidad, Secretaría, jefes de los Departamentos Legal, Planificación, Técnico, Finanzas, Administración o sus subrogantes, quienes tienen voz y voto de responsabilidad, a excepción de la Secretaría, que únicamente dará lectura de las actas para su aprobación y registrará las resoluciones correspondientes.

El cumplimiento de los procesos con responsabilidad. - "Nos permite: 1. Garantizar la calidad del gasto público y su ejecución en concordancia con el Plan Nacional de Desarrollo; 2. Garantizar la ejecución plena de los contratos y la aplicación efectiva de las normas contractuales; 3. Garantizar la transparencia y evitar la discrecionalidad en la contratación pública; 4. Convertir la contratación pública en un elemento dinamizador de la producción nacional; 5. Promover la participación de artesanos, profesionales, micro, pequeñas y medianas empresas con ofertas competitivas, en el marco de esta Ley; 6. Agilitar, simplificar y adecuar los procesos de adquisición a las distintas necesidades de las políticas públicas y a su ejecución oportuna; 7. Impulsar la participación social a través de procesos de veeduría ciudadana que se desarrollen a nivel nacional, de conformidad con el Reglamento; 8. Mantener una sujeción efectiva y permanente de la contratación pública con los sistemas de planificación y presupuestos del Gobierno central y de los organismos seccionales; 9. Modernizar los procesos de contratación pública para que sean una herramienta de eficiencia en la gestión económica de los recursos del Estado; 10. Garantizar la permanencia y efectividad de los sistemas de control de gestión y transparencia del gasto público; y, 11. Incentivar y garantizar la participación de proveedores confiables y competitivos en el SNCP" (Servicio Nacional de Contratación Pública, 2019)

\section{Conclusiones.}

- La experiencia obtenida en nuestra actividad de investigación, dio como resultado en que se debe modificar la presentación de garantías o caución por parte de funcionarios que presten servicios en las instituciones públicas del Estado Ecuatoriano, garantías que presentarán por los montos establecidos como base mínima del sistema de procedimiento para adjudicar contratos por medio de licitaciones, que deben ser garantías mediante la presentación de hipotecas o de Seguros calificados, cuyos gastos correrán por cuenta de los propios funcionarios responsables del manejo de recursos financieros o económicos por parte de las máximas autoridades, jefes departamentales de todo orden y servidores como contadores, pagadores, guardalmacenes, quienes asumen directamente la responsabilidad de todo hecho que afecte económicamente o cometa fraudes al Estado.

- La investigación efectuada a dos procesos diferentes de contratación pública, nos ha dado mayor visión sobre el manejo de los recursos del Estado Ecuatoriano, por lo que nos dio mayor claridad de que un contrato por obra y puede ser también 
por adquisiciones de bienes o servicios de mayor cuantía, tienen mayor oportunidad de cometer actos de corrupción, pues en los casos de capacitación, como en nuestro ejemplo, hubo propuestas de Operadores representando a fundaciones y otros, quienes demostraron responsabilidad tanto en la institución contratante como en el contratista, debiendo confirmar que hubo además buena administración y coordinación para el cumplimiento del contrato, que además los dos contratos habían sido examinados por la Contraloría General del Estado.

\section{Referencias Bibliográficas}

Contraloría General del Estado. (2014). Normas de Control Interno de la Contraloría General del Estado. Quito: CGEE.

Contraloría General del Estado Ecuador. (2014). Normas de control interno . Quito: Registro Oficial.

Estado Ecuatoriano. (22 de febrero de 2001). Ley de contratación pública. Registro Oficial, pág. 2.

SERCOP. (2019). Montos de contratación pública. Obtenido de https://portal.compraspublicas.gob.ec/sercop/montos-de-contratacion-2019/

Servicio Nacional de Contratación Pública. (diciembre de 2019). Instructivo Técnico . Quito, Pichincha, Euador: SNCP.

Szczaranski Cerda, C. L. (2011). Rol de las empresas, responsabilidad penal de las personas juridicas y corrupción. Santiago: VID. 


\section{PARA CITAR EL ARTÍCULO INDEXADO.}

Paula Alarcón, G. V., \& Gallegos Santillán, D. N. (2021). Prácticas del control previo para evitar corrupciones. Visionario Digital, 5(4), 42-57. https://doi.org/10.33262/visionariodigital.v5i4.1896

\section{¿Ciencia}

El artículo que se publica es de exclusiva responsabilidad de los autores y no necesariamente reflejan el pensamiento de la Revista Visionario Digital.

El artículo queda en propiedad de la revista y, por tanto, su publicación parcial y/o total en otro medio tiene que ser autorizado por el director de la Revista Visionario Digital.
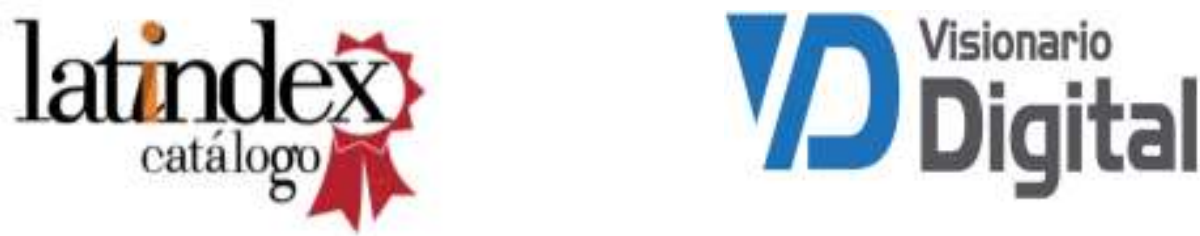